\title{
Ruprecht Majewski-Bosma syndrome associated with atrial septal defect
}

Aamir Jalal Al Mosawi

Advisor in Pediatrics and Pediatric Psychiatry, Children Teaching Hospital of Baghdad Medical City, Head, Iraq Headquarter of Copernicus

Scientists International Panel Baghdad, Iraq.

Corresponding Author: Aamir Jalal Al Mosawi, Advisor in Pediatrics and Pediatric Psychiatry Children Teaching Hospital of Baghdad

Medical City E-Mail: almosawiAJ@yahoo.com

Received date: November 11, 2019; Accepted date: December 02, 2019; Published date: December 09, 2019

Citation: Aamir Jalal A, M., (2019) The case number 52 of Ruprecht Majewski-Bosma syndrome associated with atrial septal defect. International Journal of Clinical Case Reports and Reviews. 1(1); DOI:10.31579/2690-4861/001

Copyright:@2019 Aamir Jalal Al Mosawi, This is an open-access article distributed under the terms of the Creative Commons Attribution License, which permits unrestricted use, distribution, and reproduction in any medium, provided the original author and source are credited.

\section{Abstract}

Background: Ruprecht Majewski-Bosma syndrome is an extremely rare dysmorphic syndrome results from severe hypoplasia of the nose and eyes occurring in association with palatal abnormalities.It is characterized by congenital complete nasal agenesis (Bilateral aplasia of the nose), microphthalmia including clinical anophthalmia, hypertelorism and other eye defects, high arched palate, and other palatal defects.

Materials and methods: A full term newborn female born to a consanguineous parents in their twenties with multiple congenital abnormalities was observed and studied at Children Teaching Hospital of Baghdad Medical City. The relevant literature was reviewed.

Results: At birth the girl had the characteristic congenital abnormalities Ruprecht Majewski-Bosma syndrome of including complete nasal agenesis (Bilateral aplasia of the nose), bilateral microphthalmia, high arched palate, hypertelorism, and secondum atrial septal defect.

Literature review confirmed the extreme rarity of the condition. Becerra-Solano et al (2016) reported the fifteenth case of the syndrome in the literature. The case of Mondal and Prasad was most probably the reported case number fifty one. Congenital heart defects have not been reported in association with this syndrome.

Conclusion: The paper reported the fifty two patients with Ruprecht Majewski-Bosma syndrome which is the first case of the syndrome to be associated with congenital heart defect, atrial septal defect.

Keywords: ruprecht majewski-bosma syndrome; iraq; atrial septal defect

\section{Introduction}

Ruprecht Majewski-Bosma syndrome is an extremely rare dysmorphic syndrome results from severe hypoplasia of the nose and eyes occurring in association with palatal abnormalities.It is characterized by congenital complete nasal agenesis (Bilateral aplasia of the nose), microphthalmia including clinical anophthalmia, hypertelorism and other eye defects, high arched palate, and other palatal defects. Patients commonly needs few weeks to learn how to breathe through their mouth, and how to breathe and eat at the same time. Therefore, they usually need oral airway during the first few weeks or months of life. They cannot smell because they are lacking the internal parts of the smell (olfactory) system, but they may be able to detect very strong, irritating odors. Later, patients need plastic surgery to build an external nose. Small penis and undescended testes (cryptorchidism) have been attributed to defective hypothalamic production of gonadotropin-releasing hormone [1, 2, 3, 4].

\section{Materials and methods}

A full term newborn female born to a consanguineous parents in their twenties with multiple congenital abnormalities was observed and studied at Children Teaching Hospital of Baghdad Medical City. The relevant literature was reviewed.
The mother experienced three abortion before this girl was born. During pregnancy the mother experienced fever and was treated with a course of parental antibiotics. The girl was delivered by cesarean section because of lack of progress in labor.

\section{At birth congenital abnormalities included:}

1-Complete nasal agenesis (Bilateral aplasia of the nose) causing difficulty in breathing requiring the use of airway piece and orogastric tube feeding (Figure-1).

2- Bilateral microphthalmia (Figure-1).

3- High arched palate (Figure-1).

4-Hypertelorism.

5-Low set ears.

6-Large size aneurysmal secondum atrial septal defect.

\section{Results}




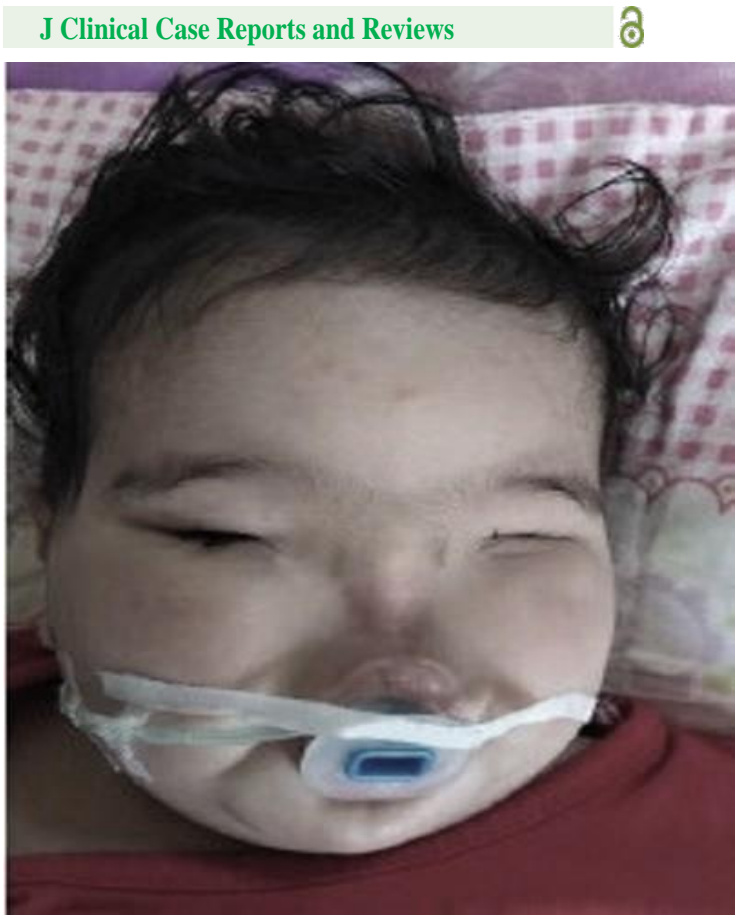

Figure-1: The girl had complete nasal agenesis causing difficulty in breathing requiring the use of airway piece and orogastric tube feeding

Radiologic studies showed absent nasal cavity, poorly developed nasal septum, bilateral small maxillary antrums, non-fusion of both zygomatic bones, and absence of cribriform plate.

At the age of six months, her growth and development were satisfactory and it was to remove the airway piece and oro-gastric tube with establishment of normal breathing (Figure-2) and on oral feeding.

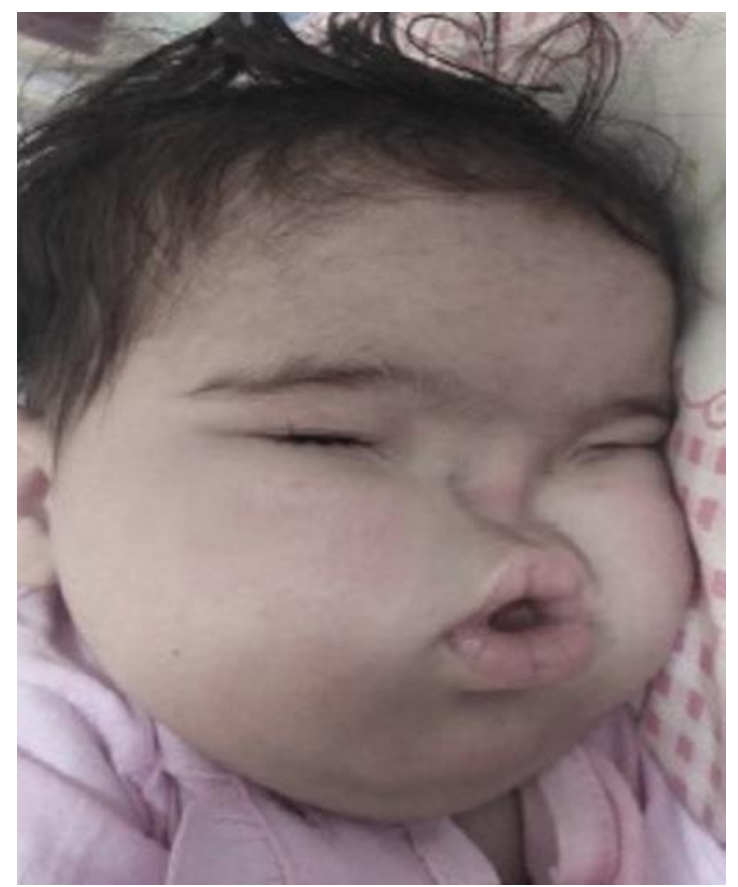

Figure-2: At the age of six months, it was to remove the airway piece and oro-gastric tube with establishment of normal breathing

\section{Discussion}

In 1978, Klaus Ruprecht and Frank Majewski described two German sisters with congenital complete absence of the nose and eye defects, choanal atresia, microphthalmia, and cleft palate. The parents were healthy, and Ruprecht and Majewski suggested that the two girls had a new autosomal recessive malformation syndrome [1].

In 1981, James Bosma, a pediatrician studied two unrelated males reported previously in 1972 by George Gifford, a plastic surgeon and colleagues. Gifford and colleagues reported two cases with congenital absence of the nose and anterior nasopharynx. When Bosma et al (1981) described the two patients of and colleagues, they reported that the also had hypoplasia of the eyes, sensory abnormalities of taste and smell, impaired vision with cataracts and colobomata, bilateral inguinal hernias, cryptorchidism, and hypogonadotropic hypogonadism. Bosma et al thought that their abnormalities resulted from an embryological disruption that occurred during the first trimester of pregnancy. The patients had normal intelligence $[2,3]$.

LaTrenta et al (1995) from the USA reported a patient with complete nasal agenesis with bilateral microphthalmia and unilateral duplication of the thumb [5].

Thiele et al (1996) reported two Germany females (aunt and niece) with variable manifestations of complete absence of the nose, microphthalmia, choanal atresia, and hypertelorism. One patient was a 5-year-old German with complete absence of the nose and nostrils, hypertelorism, microphthalmia of the left eye and right-sided clinical anophthalmia, high palate, choanal atresia, and bilateral absence of the twelfth ribs. She had normal motor and mental development. A similarly affected maternal aunt had died two hours after birth. The proband's mother and maternal grandmother both exhibited only a broad nasal tip and asymmetric nostrils, as well as high palate in the mother. Thiele et al considered the condition to have autosomal dominant inheritance with reduced penetrance [6].

Olsen et al (2001) reported a Norwegian female infant who had congenital absence of the external nose, high-arched palate, slight hypertelorism, and bilateral colobomata of the iris [7]. Hou (2004) reported a sporadic female patient with congenital absence of the external nose, bilateral microphthalmia, and iris coloboma [8].

Graham and Lee (2006) from the USA described two unrelated sporadic male patients with congenital absence of the external nose, microphthalmia, choanal atresia, cryptorchidism, hypogonadotropic hypogonadism, and normal or near-normal intelligence [9].

Brasseur et al (2016) from the USA emphasized the extreme rarity of Ruprecht Majewski-Bosma syndrome and estimated that less than 50 cases have been reported in the literature. They reported a patient who had congenital absence of the nose bilateral colobomatous microphthalmia, high arched palate, mild ear malformations, hypogonadotropic hypogonadism requiring growth hormone treatment in childhood, and normal intelligence [10].

Becerra-Solano et al (2016) reported a 19-month-old Mexican boy with congenital absence of the nose, bilateral clinical anophthalmia, choanal atresia, high palate, small penis, undescended testes, and hypoplastic scrotum. Becerra-Solano et al considered their patient to be the fifteenth case of the syndrome in the literature, and the first reported Mexican case [11]. 
hypogonadotrophic hypogonadism in two males. J Craniofac Genet Dev Biol; 1:153-184. PMID: 6802865.

Mondal and Prasad (2016) from India described a male newborn delivered at term via uncomplicated vaginal delivery and had with complete congenital absence of nose, bilateral microphthalmia, lower eyelid coloboma and feeding difficulty. The decision was made to defer reconstructive surgery to preschool age. At the age of one year, the child was feeding liquid and semisolid food and growing well. The case of Mondal and Prasad was most probably the reported case number fifty one [12].

\section{Conclusion}

The paper reported the fifty two patients with Ruprecht Majewski-Bosma syndrome which is the first case of the syndrome to be associated with congenital heart defect, atrial septal defect.

\section{Acknowledgement}

The author would to express his gratitude for the parents of the patient who accepted publishing her photos.

\section{References}

1. Ruprecht KW and Majewski F. (1978) Familiary arhinia combined with peters' anomaly and maxilliar deformities, a new malformation syndrome. Klin Monbl Augenheilkd 172: 708-715. PMID: 672092 [Article in German].

2. Gifford GH, Jr, Swanson L and MacCollum DW. (1972) congenital absence of the nose and anterior nasopharynx. Report of two cases. Plast Reconstr Surg, 50:5-12 [PMID: 5032329].

3. Bosma JF, Henkin RI, Christiansen RL Herdt JR. (1981) Hypoplasia of the nose and eyes, hyposmia, hypogeusia, and
4. Muhlbauer W, Schmidt A, Fairley J. (1993) Simultaneous construction of an internal and external nose in an infant with arhinia. Plast Reconstr Surg. 91: 720-725,. PMID: 8446727.

5. LaTrenta GS, Choi HW, Ward RF, Hoffman L, Neidich JA. (1995) Complete nasal agenesis with bilateral microphthalmia and unilateral duplication of the thumb. Plast Reconstr Surg May; 95(6):1101-4. PMID: 7732122.

6. Thiele H, Musil A, Nagel F, Majewski F. (1996) Familial arhinia, choanal atresia, and microphthalmia. Am J Med Genet; 63: 310-313. [PMID: 8723126].

7. Olsen OE, Gjelland K, Reigstad H and Rosendahl K. (2001) Congenital absence of the nose: a case report and literature review. Pediatr Radiol.; 31:225-322. PMID: 11321738.

8. Hou JW. 2004 Congenital arhinia with de novo reciprocal translocation, t $(3,12)$ (q13.2; p11.2). Am. J. Med. Genet. 130A: 200-201. PMID: 15372519.

9. Graham JM, Jr, Lee J. (2006)Bosma arhinia microphthalmia syndrome. Am J Med Genet. 140A: 189-193,. PMID: 16353241 .

10. Brasseur B, Martin CM, Cayci Z, Burmeister L, Schimmenti LA. (2016) Bosma arhinia microphthalmia syndrome: Clinical report and review of the literature. Am J Med Genet A May; 170A (5):1302-7. PMID: 26842768.

11. Becerra-Solano LE., Chacon L, Morales-Mata D., Zenteno JC, Ramirez-Duenas ML, Garcia-Ortiz JE. (2016) Bosma arrhinia microphthalmia syndrome in a Mexican patient with a molecular analysis of PAX6. Clin Dysmorph; 25: 12-15. PMID: 26440771.

12. Mondal U, Prasad R. (2016) Congenital Arhinia: A Rare Case Report and Review of Literature. Indian J Otolaryngol Head Neck Surg Dec; 68(4):537-539. PMID: 27833885. 